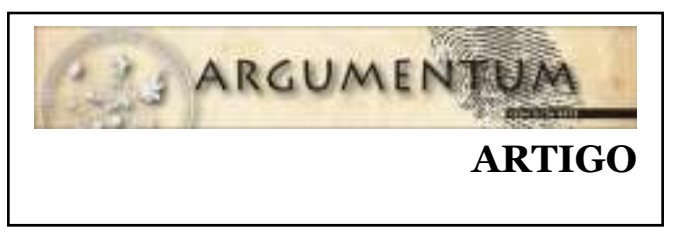

\title{
Contribuição à Crítica da Economia Política da Contrarreforma Psiquiátrica Brasileira
}

\author{
A contribution to the critique of the political economy of Brazilian psychiatric counter- \\ reforms
}

Pedro Henrique Antunes da COSTA*

http://orcid.org/0000-0003-2404-8888

\author{
Kíssila Teixeira MENDES ${ }^{* *}$ \\ http://orcid.org/0000-0002-7817-599X
}

\begin{abstract}
Resumo: O artigo esboça uma crítica da economia política da atual Contrarreforma Psiquiátrica (CP) brasileira. Recorremos a trabalhos sobre a economia política da Reforma Psiquiátrica (RP), dados orçamentários e de implantação das políticas em saúde mental (SM) de 2001 a 2019. A CP é um processo de enxugamento orçamentário, remanicomialização e mercantilização, com: retorno do hospital psiquiátrico às políticas, centralidade das comunidades terapêuticas na área de álcool e outras drogas, aumento no repasse a tais instituições e reversão da tendência de fechamento de leitos psiquiátricos e investimento em ações extrahospitalares. Trata-se de uma descontinuidade na continuidade do desenvolvimento da RP; uma expressão na SM da dinâmica neoliberal, que se intensifica em nossa realidade a partir de 2015, recrudescendo a expropriação e espoliação da classe trabalhadora e do Estado pelo capital.
\end{abstract}

Palavras-chave: Reforma Psiquiátrica. Contrarreforma Psiquiátrica. Saúde Mental. Economia Política.

\begin{abstract}
This article outlines a critique of the political economy of current Brazilian Psychiatric Counterreform. It relies on studies on the political economy of Psychiatric Reform, budgetary data, and the implementation of mental healthcare policies from 2001 to 2019. Psychiatric Counter-reform is a process of budgetary downsizing, renewed use of asylums, and commodification, with: the reappearance of psychiatric hospitals in policies, the centrality of Therapeutic Communities in the area of alcohol and other drugs, increases in the funding of such institutions, the reversal of the tendency to close psychiatric beds and reduced investment in extra-hospital actions. This constitutes a break in the continuous development of Psychiatric Reform; an expression of neoliberal dynamics in mental healthcare, which has intensified since 2015, expanding the expropriation and plundering of both the working class and the State by capital.
\end{abstract} Keywords: Psychiatric Reform. Psychiatric Counter-reform. Mental Health. Political Economy.

Submetido em: 9/3/2020. Revisado em: 7/4/2020. Aceito em: 10/4/2020.

\footnotetext{
* Psicólogo. Doutor em Psicologia. Professor do Instituto de Psicologia da Universidade de Brasília. (UnB, Brasília (DF), Brasil). Instituto Central de Ciências Sul, Campus Darcy Ribeiro, Asa Norte, Brasília (DF), CEP.: 70910-900. Email: phantunes.costa@gmail.com.

**Psicóloga. Mestre em Psicologia. Doutoranda em Psicologia na Universidade Federal de Juiz de Fora. (UFJF, Juiz de Fora, Brasil). Instituto de Ciências Humanas, Campus da Universidade Federal de Juiz de Fora, São Pedro, Juiz de Fora-MG, CEP.: 36036-90o. Bolsista de demanda social CAPES. Email: kissilamm@hotmail.com.
}

\section{$(c))$ EY}

(C) A(s) Autora(s)/O(s) Autor(es). 2019 Acesso Aberto Esta obra está licenciada sob os termos da Licença Creative Commons Atribuição 4.0 Internacional (https://creativecommons.org/licenses/by/4.o/deed.pt_BR), que permite copiar e redistribuir o material em qualquer suporte ou formato, bem como adaptar, transformar e criar a partir deste material para qualquer fim, mesmo que comercial. O licenciante não pode revogar estes direitos desde que você respeite os termos da licença. 


\section{Introdução}

$\mathrm{O}$ presente artigo objetiva esboçar uma crítica da economia política da atual Contrarreforma Psiquiátrica (CP) brasileira, contribuindo para o entendimento do cenário vigente na saúde mental (SM). Coaduna-se com a crítica de Vasconcelos (2012), para quem as principais perspectivas teórico-políticas da Luta Antimanicomial (LA) e da Reforma Psiquiátrica (RP) brasileiras, apesar das inúmeras contribuições e potencialidades, possuem limitações para apreender a dinâmica da totalidade social capitalista, as especificidades brasileiras e as implicações para a SM. Adicionalmente, segundo Alves et al. (2020), a RP no Brasil tendeu a uma desconsideração da condição dependente na dinâmica capitalista, incorrendo em limitações e problemas analíticos e de ação.

Como proposta, Vasconcelos (2012) aponta para a incorporação da "[...] economia política ao conjunto das abordagens que nos inspiram, como instrumento de análise histórica mais ampla, e, particularmente, de análise da conjuntura e das políticas sociais [...]" (VASCONCELOS, 2012, p. 18), sendo potencializada pela crítica marxista. A crítica à economia política, segundo Marx (2008), seria capaz de dissecar a "[...] anatomia da sociedade burguesa [...]” (MARX, 2008, p. 47), isto é, o conjunto das relações e forças produtivas, desvelando as reificações liberais que fundamentam, universalizam e naturalizam o modo de produção capitalista.

Coutinho (2012), a partir de Gramsci, analisou a época neoliberal - o estágio de desenvolvimento do capitalismo "[...] da globalização ou mundialização do capital, caracterizad[o] pelo predomínio de políticas neoliberais [...]” (COUTINHO, 2012, p. 117) - a partir do conceito de contrarreforma. Segundo o autor, tal período não pode ser compreendido pelo conceito de revolução passiva, também gramsciano. Os motivos seriam que tal revolução passiva seria caracterizada por um primeiro período de restauração, uma reação conservadora às reivindicações por transformações radicais vindas de baixo, e outro posterior de renovação, onde algumas dessas demandas seriam incorporadas e gerenciadas pelo alto, por meio de concessões das classes dominantes. Tal dinâmica caracterizaria, por exemplo, a formação social e o desenvolvimento capitalista brasileiros. Como o autor postula, "[...] uma complexa dialética de restauração e revolução, de conservação e modernização" (COUTINHO, 2012, p. 120, grifo nosso).

O Estado de Bem-Estar social (EBES) ou as medidas que foram nessa direção também configuraram exemplos de revolução passiva, o que no Brasil necessita de contextualização, pois não tivemos EBES. Já no neoliberalismo, o movimento é de uma restauração estrita, não havendo espaço para incorporação de demandas de baixo. Dadas as especificidades brasileiras, de um país gestado na colonização, capitalismo tardio, dependente e subordinado aos países e economias capitalistas mais desenvolvidos, o neoliberalismo, enquanto razão do estágio contemporâneo do capitalismo, passa a modular a gestão econômico política e a dinâmica social do país apenas nos anos 1990, tolhendo, inclusive, os ensejos de bem-estar da Constituição de 1988. Por outro lado, em decorrência de tais

Argum., Vitória, v. 12, n. 2, p. 44-59, maio/ago. 2020. | ISSN 2176-9575 
especificidades, mesmo com a aplicação do receituário neoliberal, pudemos ver conquistas em determinadas áreas das políticas sociais, como a promulgação e a organização do Sistema Único de Saúde (SUS), e, no âmbito da SM, a RP.

Entendemos que a reflexão de Coutinho sobre contrarreforma, referente à realidade brasileira, se adequa ainda mais ao atual período de ofensiva do capital neoliberal, que, em nossa interpretação, inicia-se a partir de 2015 e se intensifica após o golpe de 2016. No âmbito das políticas em SM, vemos o tolhimento e reversão da RP, configurando a $\mathrm{CP}$. A própria luta contra os retrocessos tem sido restrita a posturas defensivas, buscando resistir à tratorização de direitos. Ademais, no neoliberalismo, contrarreforma(s) passa(m) a ser chamada(s) de reforma(s), dado o sentido progressista do termo, vinculado aos anseios e às lutas das camadas subalternas por mudanças. Por exemplo, as reformas trabalhistas e previdenciárias - dentre outras ações - são, na verdade, contrarreformas, devido aos seus objetivos e efeitos deletérios à classe trabalhadora.

Concebemos a CP como o conjunto de ações a partir de 2015 que contradizem, se opõem ou suplantam elementos fundamentais da RP, que se origina na década de 1970, e tem na Lei 10.216/2001 seu principal marco político legal. Dentre os retrocessos, ressaltamos: 1) nomeação, em 2015, para a coordenação de SM, álcool e outras drogas do Ministério da Saúde (MS), de um ex-coordenador de manicômio e crítico da RP; 2) portaria 3.588, de 21 de dezembro de 2017, que modifica a configuração da Rede de Atenção Psicossocial (RAPS), inserindo o hospital psiquiátrico (HP) (BRASIL, 2017a); 3) nota técnica 11/2019 "Esclarecimentos sobre as mudanças na Política Nacional de Saúde Mental e nas Diretrizes na Política Nacional sobre Drogas" (BRASIL, 2019a); e 4) Política Nacional sobre Drogas (PNAD), via decreto 9.761/2019, e Lei sobre Drogas (LD), no 13.840/2019, com centralidade das comunidades terapêuticas (CTs) e abstinência como horizonte único do cuidado, desconsiderando a redução de danos (BRASIL, 2019b; 2019c).

Nesse sentido, a CP vincula-se na SM à ofensiva do capital em sua razão neoliberal, realizada desde o segundo mandato do governo Dilma Rousseff e intensificada nos de Michel Temer e Jair Bolsonaro, com a refuncionalização e redimensionamento do Estado por um projeto de austeridade e ajuste fiscal, que objetiva sustentar o atual estágio de desenvolvimento da acumulação capitalista. Com o recrudescimento do caráter parasitário e fictício do capital via financeirização é necessária uma maior apropriação e espoliação dos recursos da classe trabalhadora e do Estado. Isso significa a minimização estatal quanto ao seu papel de assegurar condições de consumo e vida à classe trabalhadora, ao passo que maximiza sua natureza de classe, financiando a sanha acumulativa do capital, sobretudo na transferência orçamentária para o pagamento dos juros da dívida pública e recrudescendo sua faceta e aparato de controle e repressão. Aliado a isso, temos uma ofensiva conservadora, com maior difusão e capilaridade do fundamentalismo religioso e, especificamente na SM, o retorno da centralidade da psiquiatria nos moldes tradicionais e seu mandato histórico de controle, ajustamento e oposição à RP brasileira, retomando a coordenação das políticas na área (NUNES et al., 2019). 
Para alcançar os objetivos propostos, recorremos a trabalhos que se debruçaram em aspectos da economia política da RP brasileira, num processo de busca não sistemática, proporcionando um olhar histórico sobre ela. Complementarmente, coletamos dados orçamentários e de implantação das políticas em SM até 2019, divulgados por meios governamentais, viabilizando um contraste entre os dois momentos, a RP e a CP. Primeiramente, apresentaremos um panorama da CP perante o desenvolvimento da RP posterior à Lei 10.216/2001, para aprofundarmos seus sentidos e as implicações.

\section{Reforma e contrarreforma psiquiátricas brasileiras: um panorama}

Mesmo com a RP, a SM não deixou de ser subfinanciada, refletindo o histórico de subfinanciamento do SUS e das políticas de saúde (TRAPÉ; ONOCKO CAMPOS, 2017). Na Figura 1, vemos que o auge do investimento em SM, entre 2001 e 2016, foi de 2,7\%. Segundo a Organização Mundial da Saúde (OMS, 2018), nos países desenvolvidos, os investimentos na área são superiores a $5 \%$ do orçamento em saúde. Com a aprovação da Emenda Constitucional 95/2016, que congela os investimentos sociais num período de vinte anos, limitados à variação inflacionária, tal panorama tende a se acentuar.

Figura 1 - Investimentos da saúde em Saúde Mental

Tabela 3 - Gastos do programa Saude Mental em relaçao aos gastos do Ministerio da Saude com açóes e servicos publicos de saùde

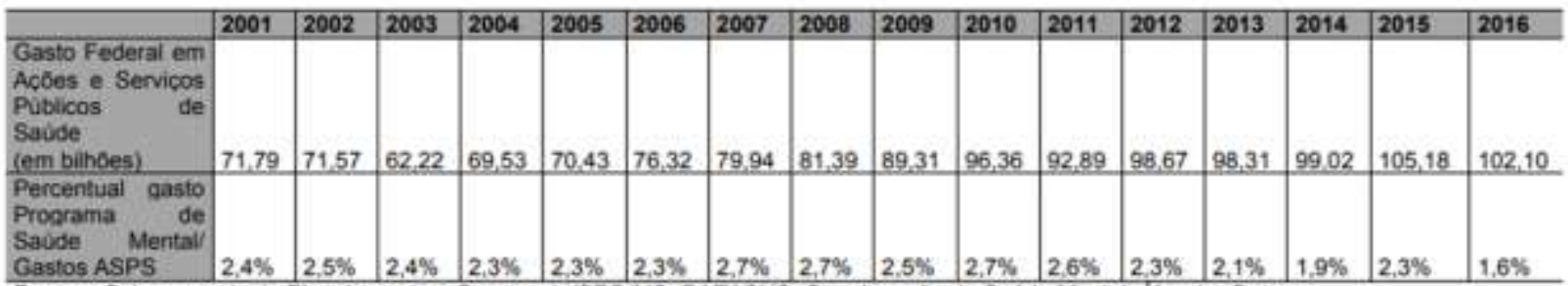

Fontes: Subsecretaria de Planejamento e Orçamento/SPO/MS, DATASUS, Cocrdenaçăo de Saude Mental, Alcool e Outras

Drogas/DAPES/SAS/MS (Valor em bilhoes de reais)

tVaior atualizado com base no IGP.DI de 2001 de 3,19; 2002 de 2,89; 2003 de 2.29; 2004 de 2, 12: 2005 de 1,89; 2006 de 1,87; 2007 de 1,80; 2008

de 1,67; 2009 de 1,53; 2010 de 1,55; 2011 de 1,39; 2012 de 1,33; 2013 de 1,23; 2014 de 1,16; 2015 de 1,12. Base de calculo 01/16.

Fonte: Extraído de Oliveira (2017).

De 2001 a 2010, observamos variações entre $2,3 \%$ e 2,7\% do orçamento da saúde destinado à SM. Entre 2011 a 2014, tais valores foram de 2,6\% para 1,9\%, aumentando em 2015 para $2,3 \%$, mas voltando à tendência de enxugamento em 2016, com 1,6\%. Temos uma diminuição gradativa, desde 2011, nos investimentos gerais em SM, indicando refluxos e fissuras na RP.

No Quadro 1, a seguir, apresentamos os valores referentes a 2017-2019. Como é possível observar, intensifica-se a tendência de diminuição, com proporções (1,1-1,2\%) menores que a metade das encontradas no início dos anos 2000. Com isso, assinalamos que o movimento da CP tem como um de seus pilares a intensificação do estrangulamento orçamentário da área, principalmente a partir de 2016. 
Quadro 1 - Proporção orçamentária para a Saúde Mental

\begin{tabular}{|l|c|c|c|}
\hline & 2017 & 2018 & 2019 \\
\hline Orçamento da saúde & R\$120 bilhões & R\$121 bilhões & R\$147 bilhões \\
\hline Orçamento para a SM & $\begin{array}{c}\text { R } \$ 1,3 \text { bilhão (aprox. } \\
1,1 \%)\end{array}$ & $\begin{array}{c}\text { R } \$ 1,5 \text { bilhão (aprox. } \\
1,2 \%)\end{array}$ & $\begin{array}{c}\text { R } \$ 1,6 \text { bilhão (aprox. } \\
1,1 \%)\end{array}$ \\
\hline
\end{tabular}

Fontes: Dados do Portal da Transparência (BRASIL, 2020) e Ministério do Desenvolvimento Humano (AGÊNCIA SAÚDE, 2019).

Conforme a Figura 2, de 2001 a 2016 houve uma tendência de diminuição nos investimentos hospitalares (internação e procedimentos em hospitais psiquiátricos e gerais). Complementarmente, cresceram os investimentos extra-hospitalares (serviços e ações comunitários) até o ano de 2010. Em 2006, pela primeira vez, os investimentos extrahospitalares ultrapassaram os hospitalares. Segundo Gonçalves, Vieira e Delgado (2012), entre 2001 e 2009, o aumento dos valores extra-hospitalares foi de $404,2 \%$, enquanto os hospitalares decresceram 39,5\%. Contudo, tal como observado no orçamento geral, de 2011 a 2014, as verbas para ações e serviços extra-hospitalares diminuíram paulatinamente, com aumento em 2015 e novo decréscimo em 2016. Uma das consequências mais sensíveis dessas mudanças é a redução do ritmo de criação de novos dispositivos comunitários, como os CAPS, as residências terapêuticas, dentre outros. Segundo Onocko-Campos (2019), "[...] a expansão de serviços comunitários está praticamente estanque após 2011” (ONOCKOCAMPOS, 2009, p. 11).

Figura 2 - Comparação de investimentos hospitalares e extra-hospitalares (2001-2016)

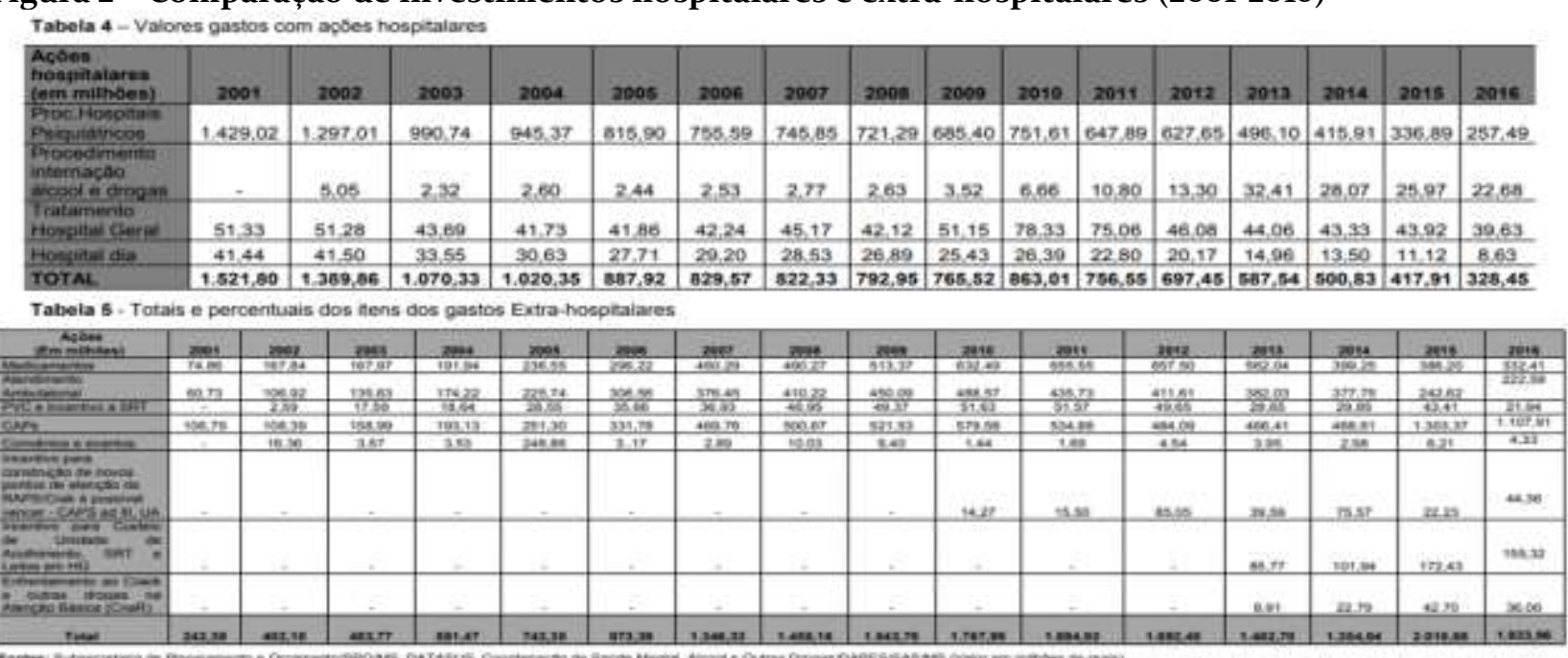

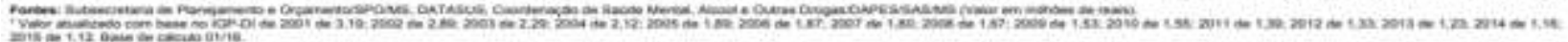

Fonte: Extraído e adaptado de Oliveira (2017).

Outro ponto pertinente é que a maior parte dos investimentos hospitalares sempre foi destinada aos HPs. Por exemplo, em 2016, $78 \%$ das verbas hospitalares foram para HPs. Comparativamente, os hospitais gerais, as instituições públicas para o cuidado requerente de internação de curto ou curtíssimo prazo, obtiveram apenas 12\% (Figura 2). 
Em 2017, a Portaria 3.588 inseriu o HP na RAPS. Não há, portanto, mais serviços e níveis substitutivos (afinal, eram substitutivos ao HP); são todos complementares. Posteriormente, outra Portaria, a 2.434 de agosto de 2018, reajustou os valores de internações psiquiátricas em HPs, com aumento de até $65 \%$ nos casos de curta permanência (inferior a 90 dias) e nova internação com mais de trinta dias (BRASIL, 2018a).

De acordo com o MS (BRASIL, 2017b), do reforço de R $\$ 320$ milhões destinados para a expansão da RAPS no ano de 2018, R\$10o milhões eram previstos para as CTs. Ou seja, 31\% desse investimento para instituições não governamentais e asilares, contrárias aos pressupostos da RP. Nesse ínterim, a Portaria 3.659, de novembro de 2018, suspendeu R \$77 milhões de custeio mensal para alguns dispositivos públicos da RAPS, sobretudo os CAPS (BRASIL, 2018b). No mesmo mês, a Portaria 3.718 (BRASIL, 2018c) retraiu mais R $\$ 43$ milhões destes serviços, sob o argumento inédito de devolução de recursos supostamente não executados.

Considerando estas mudanças enquanto parte de um todo - a $\mathrm{CP}$-, que expressa um projeto político e as ramificações na SM, é possível constatar seu objetivo de fomento às ações e aos serviços extra-hospitalares. Tal caminho mostra-se ainda mais temerário quando fomentam os HPs e seu passado e presente de violações de direitos (CONSELHO FEDERAL DE PSICOLOGIA, 2019). Não se trata de uma negação per se dos serviços hospitalares e da internação enquanto possibilidades assistenciais, mas de crítica ao indulto estatal a essa prática em instituições assentadas na lógica manicomial, mesmo que escamoteada por discursos e tecnicalidades, amalgamadas à sua natureza não-governamental mercantil, enquanto suprime verbas dos dispositivos assistenciais públicos e, assim, se orienta para o desmonte e deslegitimação da RP e SUS.

Algumas dificuldades perpassaram a busca por informações no período pós-2016. Como razões para isso, apontamos a menor transparência na divulgação das ações realizadas pelos governos (ONOCKO-CAMPOS, 2019). Além disso, focamos em dados e movimentações do MS; com as reorganizações ministeriais nos governos Temer e Bolsonaro, apesar de a Política Nacional de Saúde Mental ainda ser coordenada pelo MS, parte de sua estrutura e atribuições, sobretudo no que se refere a álcool e outras drogas, foi dissociada da SM e transferida a outros ministérios. No primeiro governo, para o do Desenvolvimento Social e Agrário, e, no segundo, para o da Cidadania, ambos coordenados por Osmar Terra, deputado federal e psiquiatra, ligado à Associação Brasileira de Psiquiatria e CTs.

Ao contrário de uma visão linear sobre o desenvolvimento da RP brasileira, levando a uma conclusão igualmente linear e etapista de "[...] progresso, estagnação e recuo [...]" (NUNES et al., 2019, p. 4491), entendemos tal processo em suas contradições, expressando antagonismos estruturais, disputas e tensionamentos. Nada é mais evidente que a própria Lei 10.216, apresentada como projeto em 1989 (no 3657), passando por disputas, modificações e sendo aprovada quase 12 anos depois. Assim, estagnações e recuos, são observados em todo o desenvolvimento da RP, não somente no período da CP. Queremos dizer que o avanço da RP foi conformado, dialeticamente, por estas estagnações e recuos. 
De maneira mais clara possível: alguns dos fundamentos da $\mathrm{CP}$ ou os retrocessos concretizados nela/por ela são observados no próprio desenvolvimento da RP.

Tal interpretação coaduna com a de Alves et al. (2020). Ao analisarem os desdobramentos da política de SM em São Paulo (SP), entre 2008 e 2017, à luz da Teoria Marxista da Dependência, constataram, em meio aos seus avanços, sua incompletude, limites e contradições. Segundo os autores, uma manifestação da relação arcaico-moderno que caracteriza nosso desenvolvimento enquanto país-nação na SM. Seguindo nessa apreensão dialética, a CP é uma descontinuidade da RP, na continuidade de seu desenvolvimento. Não é a RP propriamente dita, ou uma nova fase dela, pois se opõe e suplanta seus preceitos e fundamentos. Também não é a reforma da Reforma, devido ao sentido histórico do termo e como tem sido cooptado no neoliberalismo, conforme alertou Coutinho (2012). Entretanto, a CP brasileira progrediu, avançou e alguns de seus pontos até floresceram no seio da RP.

\section{A ofensiva do capital e o retorno do que não foi: mercantilização e manicomialização}

A partir dos dados apresentados, conclui-se que a vigente CP brasileira implica em um processo de enxugamento orçamentário, numa área cronicamente subfinanciada, e remanicomialização, com: institucionalização do HP na RAPS, atualização e aumento no repasse para tais instituições, juntamente com a reversão da tendência da RP de fechamento de leitos psiquiátricos e dos investimentos extra-hospitalares. Grosso modo, o retorno do que não foi: do HP enquanto instituição materializadora da lógica manicomial. Por sua vez, o HP deve ser compreendido na e pela concretude histórica a qual se vincula, e produz; em nosso caso, como uma expressão das configurações presentes do modo de produção capitalista na periferia do sistema, de constituição colonial.

Reforçamos, assim, a necessidade de compreensão da relação normal patológico, dos chamados desvios, em suma, da drogadição, loucura e saúde mental, imbricadas e consubstanciadas na/pela normalidade produtiva do modo de produção capitalista. Sendo a lógica manicomial resultante dessa sociabilidade e, portanto, funcional a ela, não há possibilidade de ser suplantada dentro da ordem capitalista que lhe produz e é conformada por ela. Enquanto houver capitalismo haverá manicomialização, com RP ou não. E, quando consideramos nosso processo formativo, de base colonizada, escravocrata, com um capitalismo dependente, vemos os fundamentos e substratos da manicomialização segregação/asilamento, controle e violência - não apenas no tratamento do sofrimento mental, mas no trato à classe trabalhadora como um todo. Por outro lado, apesar de necessária, a supressão do modo de produção capitalista é insuficiente per se para a superação da lógica manicomial.

Apesar da relevância da RP, isso serve como alerta para que se evite posturas romantizadas de que ela seja capaz, ainda mais por dentro da ordem, de transformar radicalmente a forma como compreendemos e nos relacionamos com a loucura, o mundo e si próprios, suprimindo a lógica manicomial. Não obstante, que a Reforma deve se submeter a um 
projeto mais amplo, revolucionário e anticapitalista, vinculando-se a outros âmbitos e indo além do aparato estatal e políticas sociais.

Enriquecendo o debate, Richard Warner (2004), ao analisar distintos contextos societários, constatou uma relação proporcional entre as configurações do mundo do trabalho no capitalismo e as formas de tratamento para pessoas com esquizofrenia. Em cenários com altas taxas de emprego e melhores condições de trabalho, observou maiores fomentos e taxas de reabilitação de esquizofrênicos, em contraposição a medidas asilares. $\mathrm{O}$ inverso também foi notado, com períodos de intensificação do desemprego, de retração ou estagnação econômica e pioras nas condições de trabalho, sendo constituídos por aumento nas taxas de internações, sobretudo, em HPs, em vez de ações comunitárias.

Cabe ressaltar que o desemprego no capitalismo é estrutural. A parcela da população alijada do mercado formal de trabalho, nas variadas formas que vão desde o desemprego e o desalento, até as cada vez mais comuns modalidades informais, constitui uma massa sobrante, um exército industrial de reserva e a superpopulação relativa, tomada como alavanca de acumulação capitalista e alicerce para a manutenção rebaixada ou, mesmo, o retraimento dos patamares salariais, pioras nas condições de trabalho e perdas de direitos. Na condição dependente brasileira, temos ainda a superexploração da força de trabalho como um de seus pilares, uma compensação às diferentes formas de transferência de valor para as economias centrais.

Analisando a realidade brasileira e seu movimento recente, constata-se a pertinência das conclusões de Warner. A diminuição dos investimentos hospitalares e o aumento nos extrahospitalares a partir de 2001, mas, sobretudo de 2006 a 2010, acompanhou a queda no desemprego, que chegou, durante os anos de 2013 e 2014, aos menores patamares já registrados (4,3\%) (INSTITUTO BRASILEIRO DE GEOGRAFIA E ESTATÍSTICA, 2020). A despeito de algumas variações, isso nos faz refletir que em um panorama de pleno emprego nos moldes capitalistas, há a necessidade de maior incorporação dos loucos da classe trabalhadora, até então desconsiderados em decorrência das incapacidades de produzirem dentro da normalidade requerida. Com a intensificação da massa sobrante - dado os crescentes patamares de desemprego, que desde 2015 giram em torno de 10 a $13 \%$, de desalento e do trabalho informal - as pessoas acometidas por transtornos mentais deixam de ser requisitadas como trabalhadores, produtores de mais valor, na mesma quantidade que antes, nem sob as formas usuais de subemprego, ao menos nos padrões específicos de produtividade. Isso não significa que se tornem descartáveis, pois suas segregações não significam exclusões sociais, sendo lucrativas perante os anseios acumulativos. O retorno dos HPs nas políticas de SM, com aumento de verbas num período de austeridade, demonstra como que a manicomialização é também processo de mercantilização da vida algo inerente ao capitalismo, que tem na mercadoria sua forma elementar e na consequente mercantilização do ser humano e suas necessidades.

Conforme a anormalidade se intensifica e normaliza, expressando o caráter barbarizante do atual estágio de desenvolvimento capitalista, outro paradoxo se assenta: mais sofrimento

Argum., Vitória, v. 12, n. 2, p. 44-59, maio/ago. 2020. | ISSN 2176-9575 
para os trabalhadores, com uma precarização objetiva subjetiva da vida, impactando negativamente na produção. Tais perdas, entretanto, não esmorecem as bases do sistema, pois movimentam um complexo médico farmacêutico e, no nosso caso, da indústria da loucura, bastante lucrativos, compensando possíveis perdas provocadas pelo maior sofrimento. Outras ações e contrarreformas são implementadas conjuntamente, precarizando as condições de trabalho, aumentando a jornada, desmontando o setor de previdência social, restringindo ou impossibilitando aposentadorias, praticamente obrigando que as pessoas, mesmo em piores condições, continuem a trabalhar e produzir. Nisso, o capital diminui os encargos com o colchão protetivo de direitos e toma para si as verbas estatais poupadas com estas ações, contribuindo para a ainda maior concentração e centralização de riqueza. Alia-se a isso, o recrudescimento de estratégias de controle, repressão e ajustamento.

Justifica-se a diminuição orçamentária na $\mathrm{CP}$ para serviços e ações extra-hospitalares, em um marco geral de corte de verbas, e o aumento para os hospitalares, assim como o retorno dos HPs e asilamento nas políticas. Forma-se uma amálgama com os demais processos de gerência neoliberal, de contrarreforma (COUTINHO, 2012), intensificados pela ofensiva do capital, como o saqueio do fundo público pelo capital, mercantilização, filantropização, terceirização e privatização; em suma, a espoliação e expropriação da classe trabalhadora e do Estado. Novamente, tudo isso nos leva a compreender a manicomialização também como processo de mercantilização das políticas sociais. Se não fosse, o Estado criaria seus próprios manicômios, em vez de repassar verba aos privados.

É pertinente refletir sobre os porquês das diferentes incorporações e funcionalidades das frações da classe trabalhadora no decorrer do capitalismo, considerando a saúde mental. Andrew Scull (1984), analisando os EUA e Inglaterra, mostra que os processos extrahospitalares e comunitários de desinstitucionalização na SM vincularam-se à welfarização nos anos 1960 e 1970, e à adoção de políticas de bem-estar social. Isso não significou menos capitalismo ou uma rota alterada no seu fluxo; apenas uma forma específica no seu transcorrer histórico, implicando em mudanças nas funções e papel do Estado, vinculadas à correlação de forças pós-segunda guerra mundial, à capacidade de organização e tensionamento da classe trabalhadora e ao fantasma socialista.

Além disso, tais formas comunitárias, extra-hospitalares, não são homogêneas. Conforme a Figura 2, a segunda maior dotação orçamentária extra-hospitalar foi para os medicamentos, apenas menor que a dos CAPS - em alguns anos foi até maior (OLIVEIRA, 2017). A despeito da importância dos medicamentos, é premente conceber que por extra-hospitalar não, necessariamente, temos uma oposição à lógica de controle manicomial; talvez não tão visível e abrupta fisicamente, mas não menos perversa, por processos de (psico) patologização e medicalização da vida, também aprisionantes e docilizantes. Alia-se a isso a incorporação da lógica neoliberal de mercado na gerência das políticas - o gerencialismo de Estado -, pautada pela dinâmica do desempenho, que têm em tais ações e serviços extrahospitalares, comparados aos hospitalares, tendências de maior custo-benefício. 
No Brasil, a tentativa de formulação e implementação de um EBES pela Constituição de 1988, com todas as suas contradições, foi tolhida logo no governo neoliberal de Fernando Collor de Mello. Sem embargo, só foi possível a RP germinar e se desenvolver, mesmo no neoliberalismo brasileiro, impulsionada por um conjunto de reivindicações e mobilizações que deságuam nas inclinações de bem-estar social das políticas, como o SUS. Conforme Vasconcelos (2012), discorrendo sobre a obra de Scull, “[...] quando as políticas sociais universais são sucateadas, as possibilidades de uma reforma psiquiátrica antimanicomial ser abrangente e bem-sucedida, com suporte efetivo e intersetorial na cidade, diminuem sensivelmente" (VASCONCELOS, 2012, p. 16). Com o desmonte, focalização em detrimento de universalização, terceirização e privatização das políticas sociais, intensificados pela ofensiva do capital neoliberal, mais do que nunca a RP é colocada em xeque.

Assim, muitas das limitações e contradições da RPdevem ser analisadas historicamente na totalidade social, considerando os paradoxos das políticas enquanto mediações do Estado capitalista, e da dinâmica específica da sociedade brasileira e seu capitalismo dependente. Por exemplo, a articulação entre arcaico (a manutenção de fenômenos asilares) e moderno (as propostas substitutivas) na RP, conforme Alves et al. (2020), é uma expressão nas especificidades da SM de nosso processo formativo.

Um importante complemento ao tratamento das questões tradicionais da SM encontra-se nas CTs. Inseridas na RAPS desde a sua instituição (BRASIL, 2011), as CTs obtém ganho crescente de poder econômico político, com a regulamentação no Sistema Nacional de Políticas sobre Drogas em 2015. Tal relevância encontra, com as novas velhas PNAD e LD, de 2019. As Cts, sob a alcunha de Comunidades Terapêuticas Acolhedoras (BRASIL, 2019b), passam a desempenhar um papel central no cuidado, reforçando a tradicional desresponsabilização estatal na área de drogas.

Em março de 2019, ampliou-se o número de CTs e de vagas para internação nessas instituições financiadas pelo governo, a partir de um edital que dispensou licitação. Ao todo, 496 CTs, disponibilizando 10.883 vagas, foram financiadas pelo Ministério da Cidadania, totalizando até agosto de 2019 R \$153,7 milhões no ano (QUEIJO, 2019). Considerando o levantamento do Instituto de Pesquisa e Estatística Aplicada (IPEA, 2017) sobre tais instituições, estimou-se 1.963 mil CTs no país. Sendo assim, 25\% delas são financiadas diretamente apenas por um ministério. Comparativamente, o orçamento de 2019 para os 406 Centros de Atenção Psicossocial - Álcool e outras Drogas (CAPSad), principal dispositivo assistencial especializado na área, de orientação comunitária, territorializada e cuidado não hospitalocêntrico, foi de $\mathrm{R} \$ 158$ milhões.

Um dos três pilares constitutivos do tratamento ofertado nas CTs é o trabalho, denominado de laborterapia, mas que pode ser chamado de trabalho não-pago; os outros dois são a disciplina e a religiosidade (INSTITUTO DE PESQUISA ECONÔMICA APLICADA, 2017). Adicionalmente, temos a sua condição não-estatal e asilar, com obrigatoriedade da internação. As CTs evidenciam, portanto, o movimento de recrudescimento da mercantilização e privatização da saúde, juntamente da manicomialização e 
fundamentalismo religioso. Tais instituições são uma amálgama das prisões, HPs e igrejas (FOSSI; GUARESCHI, 2015), com as antigas fábricas (numa analogia ao regime de trabalho imposto), demonstrando a indissociabilidade da ofensiva do capital neoliberal com a ascensão conservadora.

Nos casos de dependentes de drogas, temos nas CTs um meio para que eles, a despeito de suas supostas doenças, sejam incorporados enquanto trabalhadores dentro das instituições assistenciais asilares. Melhor dizendo, as suas doenças, na forma em que são compreendidas pelo saber e prática médico psiquiátricos, vistas também como patologias da mente (toxicomania), desvio de personalidade, pecado e problema moral, são utilizadas como argumentos para que sejam ainda mais explorados, expropriados de suas forças de trabalho e do fruto delas, não sendo nem pagos por isso, numa lógica e dinâmica servil e escravizante, disfarçadas de tratamento.

Tudo isso nos remete a Fanon (2015), quando este alertou para a capacidade de o projeto colonizador - a despeito das suas especificidades na África e América Latina - domar os indivíduos por meio da pacificação psiquiatrizante, provocando sofrimento ao fazer com que se produzam na exploração e opressão, mas ocultando tal realidade ao transferir seu caráter doentio para a mente ou comportamento a serem corrigidos. Nisso, o HP - e as CTs - aparece como uma das formas de domar tal "[...] natureza insubmissa" (FANON, 2015, p. 288). Podemos elucubrar que quanto mais avança o projeto do capital e sua dominação imperialista, cuja gênese está na colonização, mais internação e asilamento requererá, bem como mais sofrimento produzirá, no que Fanon (2015), denominou de "[...] período calmo de colonização bem sucedida" (FANON, 2015, p. 288).

Atualizando as observações fanonianas para a conjuntura, o sucesso da ofensiva do capital em sua razão neoliberal, que traz consigo em nossas especificidades as estruturas do projeto colonial, depende que ela se defronte com uma parcela populacional de sobrantes cada vez maior produzida por ela mesma, decorrente do ataque à classe trabalhadora e precarização da vida. Sendo tal ofensiva contra esta classe, ela cria para si um empecilho, num primeiro momento: o que fazer com tal rebotalho avolumante, que sabemos ter cara, cor, raça, etnia, gênero e localidade? O capitalismo gera nas suas contradições internas os problemas que podem indicar sua finitude, mas é também bastante eficaz no seu ocultamento e prolongamento de sua sobrevivência. Os dados de homicídios crescentes, atingindo patamares recordes, com o Estado e seu braço repressivo na segurança pública sendo os principais impulsionadores (FÓRUM BRASILEIRO DE SEGURANÇA PÚBLICA; INSTITUTO DE PESQUISA ECONÔMICA APLICADA, 2019), denotam que a principal estratégia de controle na especificidade brasileira ainda é o genocídio e extermínio de determinados indivíduos e grupos sociais. Não obstante, temos no caso da SM, o recrudescimento do controle e coerção por uma gama de estratégias de produção de sofrimento, assujeitamento e suas respostas docilizantes, segregatórias e aprisionantes, vide o retorno do que não foi: dos HPs e manicômios, propriamente ditos, e com outras roupagens, por meio de novas velhas instituições, como as CTs. 
A partir do exposto, a própria economia política da CP (e da RP) deve ser escrutinada em conjunto a do âmbito criminal e de segurança pública, vide as confluências e similitudes da lógica aprisionante e coercitiva neoliberal que se volta preferencialmente à classe trabalhadora e, nela, a determinados grupos sociais. O grande encarceramento vivido, que pode ser pensado apenas na/pela esfera criminal, em instituições como os presídios, deve englobar HPs, CTs e demais instituições que, a partir do aprisionamento e asilamento, tratam de contribuir para a manutenção da ordem. Tudo isso deve estar circunscrito à crítica da economia política do modo de produção capitalista, considerando sua dinâmica neoliberal e estágio de desenvolvimento, a partir das especificidades brasileiras.

\section{Considerações Finais}

Ao esboçar uma contribuição à crítica da economia política da CP brasileira, constatamos a necessidade de vincular tal conjunto de medidas à dinâmica da totalidade capitalista em seu atual estágio de desenvolvimento, considerando as especificidades de um país periférico com constituição colonial e capitalismo dependente. Grosso modo, o recém processo de (re)manicomialização deve ser compreendido enquanto expressão, na SM, da dinâmica neoliberal e seu caráter de contrarreforma, que se intensifica em nossa realidade partir de 2015, recrudescendo também o caráter de expropriação e espoliação da classe trabalhadora e Estado pelo capital.

Nisso, temos as modificações profundas realizadas no âmbito do trabalho, o desmonte de direitos e a minimização estatal no campo das políticas sociais, e a maximização da sua ação coercitiva, precarizando ainda mais as condições objetivas e subjetivas de vida. Inserem-se nesse cenário dois fatores referentes às especificidades da SM: (a) a força histórica do complexo médico psiquiátrico privatista mercantil que retoma a centralidade da gestão das políticas; e (b) a ascensão conservadora e do fundamentalismo religioso e suas interrelações com o Estado, com impactos mais visíveis na área de álcool e outras drogas.

Por fim, demonstramos a pertinência da crítica à economia política marxista no escrutínio da dinâmica capitalista em nossa atualidade; como a esfera política e suas decisões têm uma base econômica, material, do mesmo modo que incide nela e a conforma. Foge-se, assim, de caricaturas sobre seu suposto economicismo, evidenciando as romantizações politicistas que pressupõem ser possível modificar radicalmente a forma como compreendemos e nos relacionamos com a loucura, e, portanto, romper com a lógica manicomial, sem a supressão do capitalismo. Com isso, reforçamos a RP brasileira e suas conquistas, ainda mais quando contrastadas com os retrocessos da $\mathrm{CP}$, mas analisando-a criticamente à luz da totalidade $\mathrm{e}$ especificidades brasileiras, e submetendo-a a um projeto social revolucionário e emancipador.

\section{Referências}

ALVES, D. F. A. et al. Reforma Psiquiátrica e a Dependência Brasileira: entre o arcaico e o moderno. R. Katál., Florianópolis, v. 23, n. 1, p. 165-179, 2020. 
BRASIL. Ministério da Saúde. Portaria no 3088, de 23 de dezembro de 2011. Institui a Rede de Atenção Psicossocial para pessoas com sofrimento ou transtorno mental e com necessidades decorrentes do uso de crack, álcool e outras drogas, no âmbito do Sistema Único de Saúde (SUS). Brasília (DF), 2011. Disponível em:

http://bvsms.saude.gov.br/bvs/saudelegis/gm/2011/prt3088_23_12_2011_rep.html. Acesso em: 4 maio 2020.

BRASIL. Ministério da Saúde. Portaria no 3.588, de 21 de dezembro de 2017. Dispõe sobre a Rede de Atenção Psicossocial, e dá outras providências. Brasília (DF), $2017 a$. Disponível em:

http://bvsms.saude.gov.br/bvs/saudelegis/gm/2017/prt3588_22_12_2017.html. Acesso em: 4 maio 2020.

BRASIL. Ministério da Saúde. Ações de fortalecimentos da Rede de Atenção Psicossocial (Raps). Brasília (DF), $2017 \mathrm{~b}$. https://portalarquivos2.saude.gov.br/images/pdf/2017/dezembro/21/Saude-mentalCIT.pdf. Acesso em: 10 ago. 2020.

BRASIL. Ministério da Saúde. Portaria no 2.434, de 15 de agosto de 2018. Altera a Portaria de Consolidação $n^{\circ}$ 6/GM/MS, de 28 de setembro de 2017, para reajustar o valor das diárias de internação hospitalar acima de 90 (noventa) dias do Incentivo para Internação nos Hospitais Psiquiátricos. Brasília (DF), 2018a. Disponível em: http://bvsms.saude.gov.br/bvs/saudelegis/gm/2018/prt2434_20_o8_2018.html. Acesso em: 4 maio 2020.

BRASIL. Ministério da Saúde. Portaria no 3.659, de 14 de novembro de 2018. Suspende o repasse do recurso financeiro destinado ao incentivo de custeio mensal de Centros de Atenção Psicossocial (CAPS), Serviços Residenciais Terapêuticos (SRT), Unidades de Acolhimento (UA) e de Leitos de Saúde Mental em Hospital Geral, integrantes da Rede de Atenção Psicossocial (RAPS), por ausência de registros de procedimentos nos sistemas de informação do SUS. Brasília (DF), 2018b. Disponível em:

http://bvsms.saude.gov.br/bvs/saudelegis/gm/2018/prt3659_16_11_2018.html. Acesso em: 4 maio 2020.

BRASIL. Ministério da Saúde. Portaria no 3.718, de 22 de novembro de 2018. Publica lista de Estados e Municípios que receberam recursos referentes a parcela única de incentivo de implantação dos dispositivos que compõem a Rede de Atenção Psicossocial (RAPS), e não executaram o referido recurso no prazo determinado nas normativas vigentes. Brasília (DF), 2018c. Disponível em:

http://bvsms.saude.gov.br/bvs/saudelegis/gm/2018/prt3718_23_11_2018.html. Acesso em: 4 maio 2020.

BRASIL. Ministério da Saúde. Nota técnica no 11/2019, de 04 de fevereiro de 2019. Esclarecimentos sobre as mudanças na Política Nacional de Saúde Mental e nas Diretrizes 
da Política Nacional sobre Drogas. Brasília (DF), 2019a. Disponível em: http://www.mds.gov.br/webarquivos/arquivo/cuidados_prevencao_drogas/obid/legislacao /nota_saudemental.pdf. Acesso em: 4 maio 2020.

BRASIL. Decreto 9.761, de 11 de abril de 2019. Aprova a Política Nacional sobre Drogas. Brasília (DF), 2019b. Disponível em: http://www.planalto.gov.br/ccivil_03/_ato20192022/2019/decreto/D9761.htm. Acesso em: 4 maio 2020.

BRASIL. Lei 13.840, de 05 de junho de 2019. Altera a Lei no 11.343 , de 23 de agosto de 2006, para dispor sobre o Sistema Nacional de Políticas Públicas sobre Drogas e as condições de atenção aos usuários ou dependentes de drogas e para tratar do financiamento das políticas sobre drogas. Brasília (DF), 2019c. Disponível em: http://www.planalto.gov.br/ccivil_03/_ato2019-2022/2019/lei/L1384o.htm. Acesso em: 4 maio 2020.

BRASIL. Portal da Transparência - Saúde. Brasília (DF), [2020]. Disponível em: http://portaltransparencia.gov.br/funcoes/10-saude?ano. Acesso em: 10 ago. 2020.

CONSELHO FEDERAL DE PSICOLOGIA. Hospitais Psiquiátricos no Brasil: Relatório de inspeção nacional. Brasília (DF), 2019.

COUTINHO, C. N. A época neoliberal: revolução passiva ou contra-reforma?. Novos Rumos, Marília, v. 49, n. 1, p. 117-126, 2012.

FANON, F. Os condenados da terra. Juiz de Fora: Editora UFJF, 2015.

FÓRUM BRASILEIRO DE SEGURANÇA PÚBLICA; INSTITUTO DE PESQUISA ECONÔMICA APLICADA. Atlas da violência 2o19. Brasília (DF); Rio de Janeiro; São Paulo, 2019.

FOSSI, L. B.; GUARESCHI, N. M. F. O modelo de tratamento das comunidades terapêuticas: práticas confessionais na conformação dos sujeitos. Estudos e Pesquisas em Psicologia, Rio de Janeiro, v. 15, n. 1, p. 94-115, 2015.

INSTITUTO BRASILEIRO DE GEOGRAFIA E ESTATÍSTICA. Pesquisa Mensal de Emprego - PME. Séries históricas - Taxa de desocupação (Pessoas de 10 ou mais anos de idade), mar. 2002 - fev. 2016. Disponível em:

https://www.ibge.gov.br/estatisticas/sociais/trabalho/g180-pesquisa-mensal-deemprego.html?=\&t=series-historicas. Acesso em: 10 ago. 2020.

INSTITUTO DE PESQUISA ECONÔMICA APLICADA. Nota Técnica. Perfil das Comunidades Terapêuticas Brasileiras. Brasília (DF), 2017. 
GONÇALVES, R. W.; VIEIRA, F. S.; DELGADO, P. G. G. Política de Saúde Mental no Brasil: evolução do gasto federal entre 2001 e 2009. Rev. Saúde Pública, São Paulo, v. 46, n. 1, p. 51-58, 2012.

AGÊNCIA SAÚDE. MMFDH e Ministério da Saúde lançam campanha de valorização da vida e combate à depressão. Brasília (DF), set. 2019. Disponível em:

https://www.mdh.gov.br/todas-as-noticias/2019/setembro/mmfdh-e-ministerio-da-saudelancam-campanha-de-valorizacao-da-vida-e-combate-a-depressao. Acesso em: 10 agosto 2020

MARX, K. Contribuição à crítica da economia política. São Paulo: Expressão Popular, 2008.

NUNES, M. de O. et al. Reforma e contrarreforma psiquiátrica: análise de uma crise sociopolítica e sanitária a nível nacional e regional. Ciênc. saúde coletiva, Rio de Janeiro, v. 24, n. 12, p. 4489-4498, 2019.

OliVEIRA, E. F. A. Gastos da Política de Saúde Mental e os rumos da Reforma Psiquiátrica. 2017. Tese (Doutorado em Política Social)-Centro de Ciências Políticas e Econômicas, Universidade Federal do Espírito Santo, Vitória, 2017.

ONOCKO-CAMPOS, R. T. Saúde mental no Brasil: avanços, retrocessos e desafios. Cad. Saúde Pública, Rio de Janeiro, v. 35, n. 11, 2019.

ORGANIZAÇÃO MUNDIAL DA SAÚDE. Mental health atlas 2017. Geneva: WHO, 2018.

QUEIJO, D. Governo amplia vagas e regulamenta o tratamento de dependentes químicos em Comunidades Terapêuticas. Brasília (DF), 7 mar. 2019. Disponível em: http://mds.gov.br/area-de-imprensa/noticias/2019/marco/governo-amplia-vagas-eregulamenta-o-tratamento-de-dependentes-quimicos-em-comunidades-terapeuticas. Acesso em: 5 ago. 2020.

SCULL, A. Decarceration: community treatment and the deviant - a radical view. Cambridge: Polity, 1984.

TRAPÉ, T. L.; ONOCKO-CAMPOS, R. T. Modelo de atenção à saúde mental do Brasil: análise do financiamento, governança e mecanismos de avaliação. Rev. Saúde Pública, São Paulo, v. 51, n. 19, 2017.

VASCONCELOS, E. M. Crise mundial, conjuntura política e social no Brasil, e os novos impasses teóricos na análise da reforma psiquiátrica no país. Cad. Bras. Saúde Mental, Florianópolis, v. 4, n. 8, p. 8-21, 2012. 
WARNER, R. Recovery from Schizophrenia: psychiatry and political economy. New York: Brunner-Routledge, 2004.

Pedro Henrique Antunes da COSTA trabalhou na concepção e interpretação dos dados, na redação do artigo e na aprovação da versão a ser publicada.

Psicólogo. Doutor em Psicologia pela Universidade Federal de Juiz de Fora (UFJF). Professor do Instituto de Psicologia da Universidade de Brasília (UnB).

Kíssila Teixeira MENDES trabalhou na concepção e interpretação dos dados, na redação do artigo e na aprovação da versão a ser publicada.

Psicóloga e Cientista Social. Doutoranda em Psicologia na UFJF. Bolsista de demanda social CAPES. 